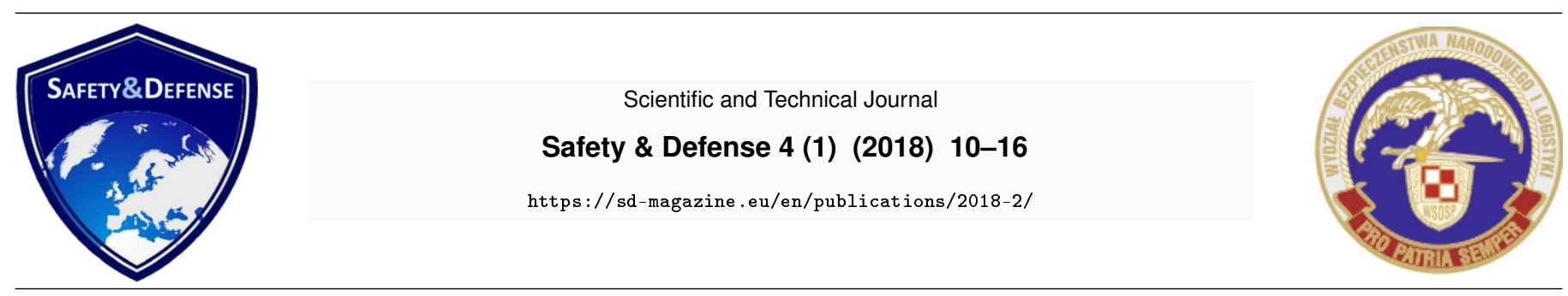

\title{
Spatial Disorientation Simulator
}

\author{
Dariusz Bogusz* \\ Aeronautics Faculty, Polish Air Force Academy, ul. Dywizjonu 303 nr 35, 08-521 Dęblin, Poland
}

\begin{abstract}
The article describes the characteristics of the spatial disorientation simulator constructed for the Polish Air Force Academy aviation training. Using the spatial disorientation simulator enables safe training for military pilots, as it simulates visual illusions and spatial disorientation. The simulator makes it possible to train pilots in spatial disorientation conditions for every possible type of aircraft, through designing and conducting the proper aircraft cabin models. Spatial disorientation training has to main aims. The first one is familiarizing the pilots with spatial disorientation phenomenon, and providing them with essential knowledge and abilities through theoretical and practical acquaintance with physiological limitations. Such limitations are related to the impact of different aviation environmental aspects on the human body. The second aim of the training is increasing the efficiency of aviation training, in relation to recognizing, analyzing and proper reacting to real and simulated occurrences, which lead to spatial disorientation. The author describes main stages of the training conducted during the spatial disorientation course. The article categorizes major features of different spatial confusion types and characterizes types of air illusions.
\end{abstract}

Keywords: simulator, spatial disorientation, spatial orientation, spatial confusion, illusions, aviation training

\section{Introduction}

The pilot's job is to carry out orders in situations which are not natural for man. Piloting, being a very complex task to do, requires the sense of spatial cognition. Spatial cognition should be defined as constant information about the plane's whereabouts, the nature of the plane's movement towards the ground surface, and other guidelines, and the parameters dynamics, which characterize the planes threedimensional space movement [1]. Modern aviation techniques improve the pilots' preparation process as they provide the candidates with extreme factors such as accelerations and overloads. Since recently, thanks to the spatial disorientation simulator, pilots can be tested in situations in which they lose the sense of orientation.

The article aims at characterizing the process of losing spatial orientation, the spatial disorientation simulator, and the major operational assumptions of the training which uses the simulator. The author argues whether using the spatial disorientation simulator enables safe training for military pilots, as it simulates visual illusions and spatial disorientation.

\footnotetext{
*Corresponding author

Email address: d.bogusz@wsosp.pl (Dariusz Bogusz)
}

Using the simulator is safe thanks to the technical development, thanks to which construction of advanced simulators is possible. Such simulators improve the efficiency and safety of aviation training realized by the Polish Armed Forces and are a proof of the constant evolution of this certain technological branch.

\section{Spatial Disorientation and Visual Illusions}

Spatial disorientation is defined as an incorrect position and movement sensation in relation to the surface of the earth. It is virtually impossible to trigger this type of phenomenon in a safe way. Moreover, typical simulators are not able to trigger such disorientation. Until 1970's it was believed the problem might be solved with the appropriate psychological preparation for fighting the spatial orientation illusions, and with detecting candidates who suffered from the disturbance of vestibular function of the ear. In that time, it was also important that the aviation personnel knew the circumstances and physiological formation mechanisms of illusions, as well as the possible ways of fighting them [2]. The technological development enabled solving the problem with the help of special equipment for pilot training in spatial disorientation causing illusions of this phenomenon through 
the appropriate interaction of movement and image. Pilots are not aware of the phenomenon when they become influenced by it, as a result of which they have a false image of reality, make an inaccurate decision which often leads to tragic events and even aviation accidents. Therefore it is crucial that they are properly prepared and familiarized with this vital phenomenon. Skillful recognition of disorientation phenomenon, acquisition and maintaining appropriate skills, as well as preference given to the instrument indications instead of individual perception can be compelling during difficult and unforeseen situations in the air. [3]

Insufficient attention paid to the position of the plane is the main reason for losing spatial orientation. Such disorientation usually occurs during a flight in weather conditions in which the horizon is not clear, or at night, when the attention is on tactical requirements or on activities performed in the cabin (e.g., switching frequency adjustment, reading the approach card).

In order to counter the spatial disorientation, the pilot needs to be mentally prepared for performing the flight in harsh weather conditions or carrying out a difficult task.

During the flight, for maintaining the situation awareness regarding the spatial location of the plane, it is important to use divided attention efficiently. It is hard to do, as its intensity increases as one enters adverse weather conditions. Moreover, it is essential to avoid those activities which imbalance the situation awareness (it is advised to use the "pilotnavigate, conduct a radio correspondence" rule).

The main reason for the occurrence of the spatial disorientation is lack of a proper attention division when it comes to decoding information from devices determining the aircraft location. Performing tactical tasks, which demand high psychological an motor burden, may lead to spatial disorientation in all weather conditions. There is a division into three main types of spatial disorientation for multipurpose airplanes.

\section{Type I: Unrecognized spatial disorientation}

During this type of disorientation, the pilot is unaware of the fact that his/her spatial location and the plane's movement differs from the pre-set one. He/she is also unaware of the disorientation which is taking place. The piloting of the aircraft is based on false perception which can lead to a collision with the ground [4].

\section{Type II: Identified spatial disorientation}

During this type of disorientation the pilot is aware of the conflict between the information from his/her body mechanisms and the ones coming from pilot devices. In most cases, the pilot is able to resolve the conflict for the benefit of the information from the devices which enables him/her to safely continue the flight [4].

\section{Type III: Overwhelming spatial disorientation}

During this type of disorientation the pilot is aware of the spatial disorientation, but he/she is not able to recover the correct flight trajectory. Visual-vestibular disorganization may be one of the factors leading to such disorientation, as it precludes decoding indications from the pilot devices or obtaining a stable image of the outdoors.

The presence of vestibular-spinal reflexes may inhibit the arm and the forearm movement making flying the plane impossible. Eventually, stress evoked by the disorientation may trigger anxiety leading to the pilot not being able to make rational decisions and "freezing", not controlling the flight [4].

Researchers argue, whether there are two or three types of spatial disorientation. The irresolvable conflict between the intellectual situation model and the data coming from the devices causes stress, which is the reason behind the third type of spatial disorientation [4].

Illusions have different definitions. They may be defined as false observation of an existing object or as a phenomenon during which a person is not aware of the error. It means that the properly received stimulus is wrongly classified. Such illusions may arise because of disrupted perception conditions, for instance in difficult weather conditions [5]. They affect sight and the vestibular system and may result in losing spatial orientation.

Polish literature classifies such illusions as presented in Table 1 [4].

\section{Disorientation Simulator}

Before introducing the spatial disorientation simulator, JAPETUS and HYPERON simulators, placed in Warsaw's Military Institute of Aviation Medicine, were used to evoke aviation illusions during the pilots' training. JAPETUS simulator is a mapped representation of the cabin and mimics the dynamics of I-22 Iryda aircraft. It is used for training and evaluating spatial orientation. Thanks to its three-channel external situation presentation structure, JAPETUS enables, among other things, false horizon simulation. Warsaw's Military Institute of Aviation Medicine has constructed HYPERION simulator to research and train the aviation personnel and to examine the pilot's fitness when it comes to spatial orientation. It is a mapped representation of the cabin of Mig-29 aircraft. Special software for the simulator has been drawn up for the spatial orientation research. As a result, it was possible to acquire simulation profiles with illusion phenomena, such as the false horizon, steadiness of size and shape [4].

Aviation training is a very expensive and complex process, which usually takes up to several years (Figure 1). Therefore, because of high expenses and the complexity of piloting, it is hard to imagine the pilot's training without using the simulator. Spatial disorientation simulator may be used since the selective stage of training, which is the first stage of aviation training. Thanks to its capabilities, it is possible to determine whether the candidate has the suitable predispositions to pilot aircraft in the recruitment process.

Spatial disorientation in aviation results in the pilot taking up inadequate actions. Such actions are defined as an error 


\begin{tabular}{|c|c|}
\hline Illusion connected to the land & $\begin{array}{l}\text { - Land without benchmarks (big snow plains, seas, deserts) } \\
\text { - "Black hole" during the landing - It makes it impossible for the pilot to properly } \\
\text { measure the altitude, because of no external benchmarks }\end{array}$ \\
\hline Illusions connected to scale & $\begin{array}{l}\text { - Atypical landing strip (angle, length, width) } \\
\text { - Big buildings } \\
\text { - Stunted trees } \\
\text { - Mountain chains }\end{array}$ \\
\hline $\begin{array}{l}\text { Illusions connected to incorrect } \\
\text { orientation }\end{array}$ & $\begin{array}{l}\text { - False horizon } \\
\text { - Skew decay of clouds } \\
\text { - Differences between lights on land and stars }\end{array}$ \\
\hline $\begin{array}{l}\text { Illusions connected to } \\
\text { movement }\end{array}$ & $\begin{array}{l}\text { - Autokinetic effect (illusionary motion) } \\
\text { - Optokinetic response (induced by the vestibular system) }\end{array}$ \\
\hline & ILLUSIONS OF VESTIBULAR ORIGINS \\
\hline Illusions connected to rotation & $\begin{array}{l}\text { - Self-rotation illusion (elongated feel of circular motion) } \\
\text { - Illusions such as Coriolis force }\end{array}$ \\
\hline Visual-vestibular illusions & $\begin{array}{l}\text { - Oculogravic illusion } \\
\text { - Oculogyral }\end{array}$ \\
\hline $\begin{array}{l}\text { Illusions connected to the } \\
\text { feeling of tilting }\end{array}$ & $\begin{array}{l}\text { - Somatogravic illusions (acceleration/breaking, centripetal acceleration, centrifugal } \\
\text { acceleration) } \\
\text { - Passive somatogravic illusions (np. roll-reversed turn and inclination) } \\
\text { - Leans } \\
\text { - Sense of increased overload }\end{array}$ \\
\hline & ILLUSIONS OF CENTRAL ORIGINS \\
\hline The brake off phenomenon & $\begin{array}{l}\text { - The pilot feels like he/she is sitting outside of the aircraft and is observing } \\
\text { himself/herself while piloting }\end{array}$ \\
\hline The "giant hand" phenomenon & $\begin{array}{l}\text { - When pilot tries to pull the plane out of disorientation, he/she wrongly perceives that } \\
\text { aircraft is not reacting to his/her actions }\end{array}$ \\
\hline $\begin{array}{l}\text { Concentrating one's attention } \\
\text { on one task }\end{array}$ & - Focusing on one detail of the task which results in losing control of the task itself \\
\hline
\end{tabular}




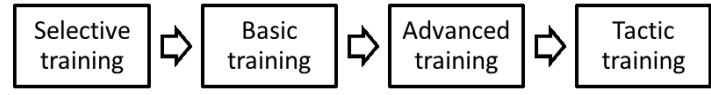

Figure 1: Stages of aviation training Source: own elaboration

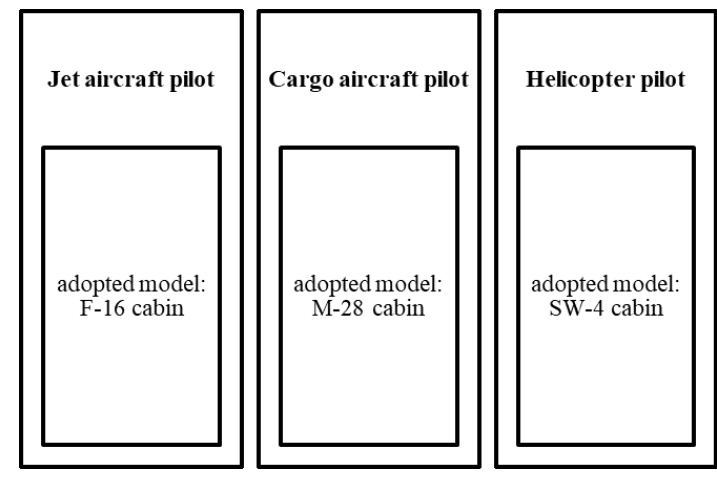

Figure 2: Aircraft cabins imitated in spatial disorientation simulator. Source: own elaboration

in piloting [4]. In order to react properly to the disorientation, ETC-PZL company, in partnership with Dęblin's Polish Air Force Academy and Warsaw's Military Institute of Aviation Medicine, designed a device which made training in spatial disorientation possible. Spatial disorientation simulator enables professional pilots and candidates for pilots to realize training. It may account for a device assessing the level of the personnel's training and may be used to select the candidates for piloting. The specialisation of particular aircraft types in the pilot's training is an important organizational factor of the training. The simulator makes it possible to train pilots in spatial disorientation conditions for every possible type of aircraft, through designing and conducting the proper aircraft cabin models (Figure 2). Constructive solutions used in the simulator make it possible to train the piloting staff, maintaining the specifics of an aircraft. What is more, the simulator's construction enables quick cabin transformation and its adaptation to the right aircraft, according to adopted model [6].

Spatial disorientation training has to main aims. The first one is familiarising the pilots with spatial disorientation phenomenon, and providing them with essential knowledge and abilities through theoretical and practical acquaintance with physiological limitations (Table 2). Such limitations are related to the impact of different aviation environmental aspects on the human body. The second aim of the training is increasing the efficiency of aviation training, in relation to recognizing, analyzing and proper reacting to real and simulated occurrences, which lead to spatial disorientation.

In order to provide the right quality of the spatial disorientation training, the training has been divided into five stages. Figure 3 shows the algorithm of the "path" which the candidate must to go through to become a pilot.

The examination takes places in the physical and mental
Table 2: Division of hours spent on spatial disorientation training

\begin{tabular}{lrr}
\hline No. & Type of training & Hours spent \\
\hline 1. & Theoretical training & 6 \\
2. & Practical Training & 30 \\
\hline & Total & 36
\end{tabular}

Source: own elaboration

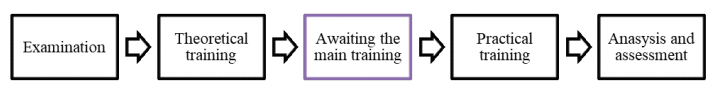

Figure 3: General scheme of spatial disorientation simulation training organization.

Source: own elaboration

stand. The pilot can proceed to theoretical training only if he/she received a positive medical conclusion.

The theoretical training includes, among other things, subjects like orientation mechanisms on and off the land, spatial disorientation (definition, the condition of its emergence, its types), simulator's characteristics (cockpit architecture, safety conditions, piloting techniques, etc.), factors leading to spatial disorientation (Table 3). During the theoretical training, the trainer discusses the scenarios, piloting parameters, communication rules, and safety issues. At the end of the theoretical training, candidates, after being familiarised with the phenomenon of spatial disorientation, fill in a questionnaire concerning their knowledge and observations.

Practical training is the next stage (Figure 4). The training is a fundamental stage of the spatial disorientation simulator training. It enables the pilot to understand the phenomenon of spatial disorientation. Practical training is conducted on spatial disorientation simulator after the candidate passes the two preceding stages. Before the training mission, every candidate carries out an instructional flight, which is aimed to familiarise the pilot with the cabin's ergonomics and the simulator's piloting characteristics for the particular aircraft. As a result, the candidate should work out a muscle mem-

Table 3: Theoretical training topics and time needed

\begin{tabular}{lrr}
\hline No. & Topic & Number of hours \\
\hline 1. & $\begin{array}{r}\text { Vestibule anatomy } \\
\text { and physiology }\end{array}$ & 1 \\
\hline 2. & Spatial orientation & 1 \\
\hline 3. & $\begin{array}{r}\text { Hazard management } \\
\text { and awareness of } \\
\text { dangerous situations }\end{array}$ & 1 \\
\hline 4. & Spatial disorientation & 3 \\
\hline & Summary
\end{tabular}




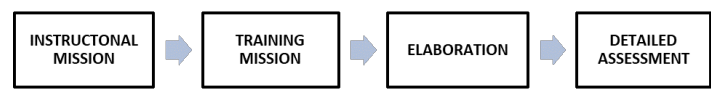

Figure 4: General scheme of spatial disorientation simulation training organization.

Source: own elaboration

ory on the requested level, which will allow to minimize the negative influence of lack of the motoric skills on the training process. The instructional flight is conducted without disorientation factors [6].

Mission training is realized individually. As a result, candidates need to wait in the room called the waiting room. The "waiting room" is exclusive for students awaiting the practical training. After finishing the training, one does not come back to the waiting room. Depending on the course of the training, the pilot-instructor can initiate activities which lead to any disorientation type. Distracting the student may be carried out by the pilot-instructor through:

- additional radio commands to be conducted by the pilot (radio channel change, visually checking if the door are closed, persistent observation of cockpit devices, etc.)

- sequential shutdown of navigation devices

- sudden change of the weather condition projection

- setting the spatial disorientation cabin into a rotating movement [6]

Individual assessment is carried out directly after finishing the practical part. Because of how long the training takes, the waiting room needs to be furnished in a way that will minimize potential negative effects, which could have an impact on one's mood.

The practical stage is carried out in a fixed order. Firstly, the candidate goes to the physical and mental examination stand so that medical devices can be attached. After checking the connection and the correct functioning of the devices the student is allowed to proceed.

Spatial disorientation simulator is technically checked before each one of the candidates. The preparation involves adapting the simulator to the right type of aircraft (jet aircraft, cargo aircraft, helicopter) and checking the technical condition. [6]

The training assessment has a brief character and takes places directly (up to twenty minutes) after finishing the training. It is best that the briefing is carried out in an auditorium, or if there is a need, in the spatial disorientation simulator room. The briefing is conducted by the pilot-instructor, the one who was supervising the training. The instructor discusses main objectives of the training, training missions used, and profile display. The instructor refers in general to the correctness of the training and initially assesses the realization of the training aims.

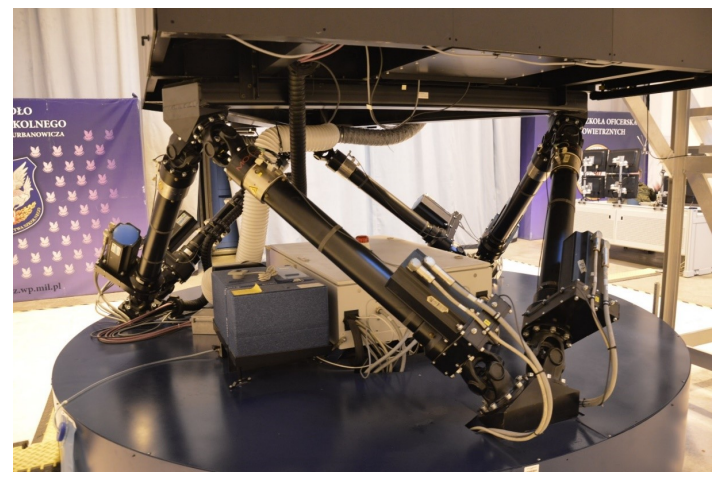

Figure 5: Spatial disorientation simulator's motion system. Source: Dariusz Bogusz

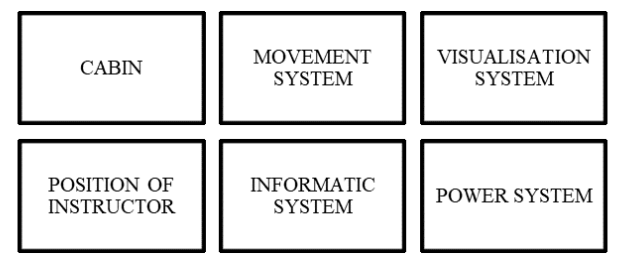

Figure 6: Main spatial disorientation simulator elements. Source: own elaboration

A detailed assessment of the pilot takes place later because it demands the analysis of all parameters from individual flights (missions).

After finishing the training, pilot fills in a questionnaire prepared by the training center. Questions aim at receiving feedback about the organizational aspects of the training, quality of the training, but foremost, about pilot's feelings regarding the profile display taking place during the practical training. The questionnaire helps assess oneself regarding the emergence of disorientation. It also helps to respond to the efficiency of the training through received theoretical knowledge and experience. [6]

The simulator is one of the most modern devices of this type in the world. The device consists of a darkened cabin (with a pilot's seat), motion system (with six levels of comfortableness), Steward's platform placed on a rotation table (with an unlimited spin number) (Figure 5), visualization system, instructor's position, IT system, and power system. (Figure 6). [6]

The disorientation simulator's cabin (Figure 7) is equipped with the basic system, which resembles jet aircraft cockpit, cargo aircraft cockpit, and helicopter cockpit. Inside the mounted cabin platform, there is a pilot's seat with switchgear and navigation-controlling devices.

Picture of the outdoor situation is presented on three panoramic monitors installed in front of the pilot (Figure 8). In order to provide a big universality of the device, there is an option of changing the side pulpits and the instrument panel. Such a solution enables training pilots for different kinds of planes and helicopters. Currently, cabins of F-16 and M-28 planes, and W-3PL helicopter are available. However, it is possible to install a replica of any plane or heli- 


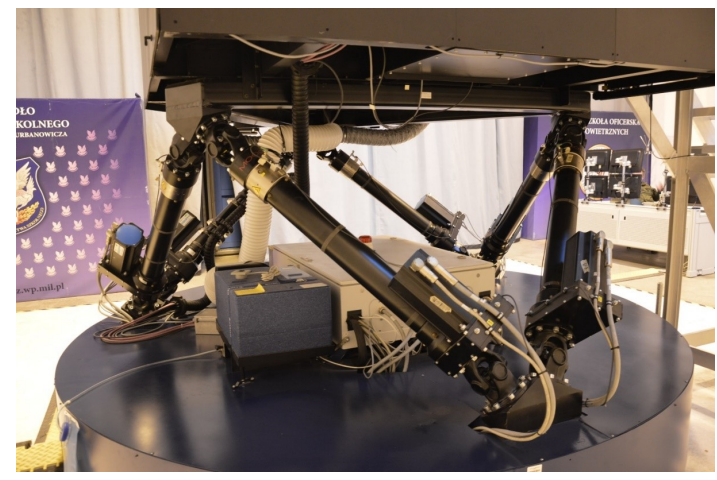

Figure 7: Disorientation simulator's cabin including the motion system. Source: Dariusz Bogusz

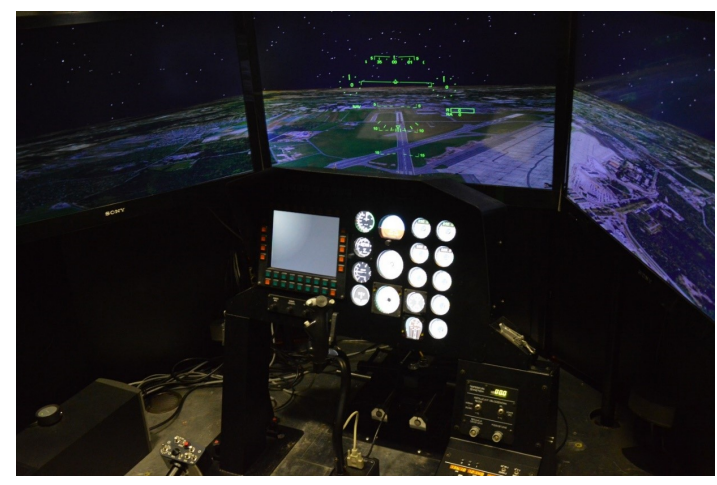

Figure 8: SW-4 helicopter cabin. Source: Dariusz Bogusz

copter. Change of the cockpit is easy, because of the big sized doors, and can be done by one person.

The training is controlled from the instructor's stand (Figure 9). The instructor can observe, among other things, the condition of deck equipment, the view of the outdoor situation, the map, and also, pilot's actions. Observation of the pilot's reaction is possible because of the installed camera and lamp operation working in the infrared spectrum. Moreover, there is a bi-directional voice connection between the instructor and the pilot.

The instructor's stand enables, among other things, conducting operational actions, checking the technical condition of the simulator, the visualisation of the image presented in the cabin and image recorded by the camera (also the pilot's face), turning off the simulator, recording and playing the process of the training (for the training assessment), and recording the radio correspondence. [6]

The IT system of the spatial disorientation simulator enables: decoding digital values of the recorded parameters at any time of the training, printing out the recorded parameters, analysing the conducted training on a supplementary monitor (so it does not disturb the simulator's work), also decoding and saving the graphical representation of the recorded parameters.

Power system provides all the elements of the simulator with safe power supply.

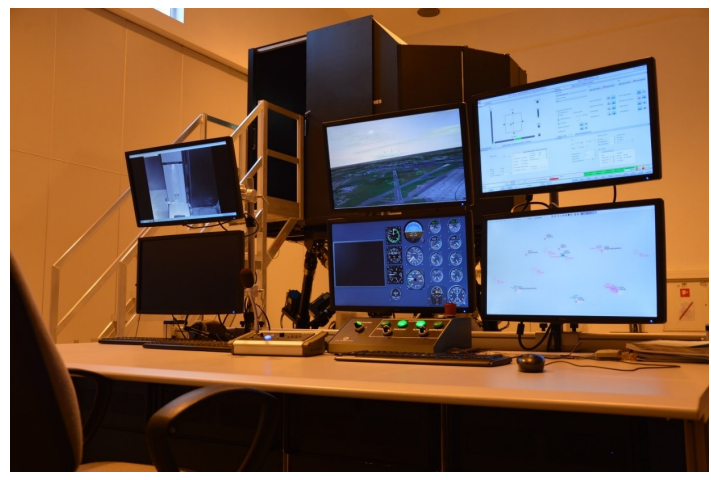

Figure 9: Instructor's stand. Source: Dariusz Bogusz

Spatial disorientation is unwanted during the flight, often leading to extreme situations, tragic in the aftermath. Spatial disorientation simulator is mainly used for teaching pilots how to handle orientation disturbance. Because of the simulator, pilots are able, in simulated conditions, to feel what one feels while being in the air. The device can imitate the most difficult flight scenarios - thirteen different variants for airplanes, nine for the helicopter. Scientists developed various aviation missions scenarios which will cause spatial disorientation. [7]

The system also enables medical examinations. While "piloting" the simulator, medical parameters are recorded to be sent to the Military Institute of Aviation Medicine in Warsaw. After the results are analyzed there, they come back do PAFA in Dęblin to help understand the phenomenon of spatial disorientation.

\section{Conclusions}

Safe triggering spatial disorientation in simulated conditions enables training pilots for losing spatial orientation. During the simulator training, candidates are able to safely experience what pilots experience on a real flight. It is crucial in spatial disorientation conditions, because decisions made during the flight may lead to aircraft accidents.

Technical development makes it possible to construct advanced simulators which enable the increase in efficiency and safety of aviation training carried out by Polish Armed Forces. Spatial disorientation simulator gives the pilots a chance to conduct piloting training in safe conditions, through simulating visual illusion and spatial disorientation. It will help in preparing the candidates for dealing with the dangerous phenomenon during a real flight.

It proves the accuracy of aviation training canon: training "on land" through using a simulator allows mistakes - training "off the land" does not forgive any mistakes.

\section{References}

[1] B. F. Łomow, K. K. Płatonow, Eksperymentalna psychologia lotnicza., Poznań: Państwowe Wydawnictwo Naukowe. (1984). 
[2] J. Terelak, Higiena psychiczna i pilot., Warszawa: Wydawnictwo MON. (1975).

[3] T. Kulik, D. Bogusz, Simulators in aeronautical training of military aviation of The Polish Armed Forces., Kosice: Acta Avionica XVII, 31 (1).

[4] H. Bednarek, Czy piloci ulegają złudzeniom percepcyjnym? Poznawcze uwarunkowania dezorientacji przestrzennej., Sopot: Gdańskie Wydawnictwo Psychologiczne. (2011)

[5] R. Makarowski, T. Smolicz, Czynnik ludzki w operacjach lotniczych. Człowiek, możliwości i ograniczenia-uwarunkowania psychofizjologiczne., Kosowizna: Adriana Aviation. (2012).

[6] M. Burek, Metodyka prowadzenia treningu na symulatorze dezorientacji przestrzennej., Dęblin: Polish Air Force Academy. (2013).

[7] M. Kowalska-Sendek, Symulator pomoże uniknąć dezorientacji., www.polska-zbrojna.pl, downloaded on: 12.01.2018] (2013).

URL http://www.polska-zbrojna.pl/home/articleshow/

9708 ? $t=$ Symulator - pomoze-uniknac-dezorientacji 